\title{
An assessment of management's attitudes and behaviour towards HIV \& AIDS at the workplace - The case of Gweru urban industries in Zimbabwe
}

\author{
Vonai Chirasha \\ Department of Human Resource Management, Midlands State University, MSU, Gweru, Zimbabwe
}

\section{Email address:}

chirashav@msu.ac.zw

\section{To cite this article:}

Vonai Chirasha. An Assessment of Management's Attitudes and Behaviour towards HIV \& AIDS at the Workplace - The Case of Gweru Urban Industries in Zimbabwe. Journal of Human Resource Management. Vol. 1, No. 4, 2013, pp. 59-63.

doi: $10.11648 /$ j.jhrm.20130104.12

\begin{abstract}
The research aimed at assessing management's personal attitudes and behaviour on HIV \& AIDS at the work place in Gweru urban industries, Midlands Province in Zimbabwe. A qualitative survey was conducted on three private organisations in Gweru. Due to the sensitivity of the information of HIV \& AIDS names of the organisations will not be published. Stratified random sampling was employed to come up with a sample size of 30 respondents. Findings revealed that indeed management was not personally involved with HIV \& AIDS programs at workplace and their behaviour and attitudes were not in support of an HIV \& AIDS free generation. The research concluded that there was need for people in positions to personalise HIV \& AIDS in the workplace. The research recommended that management should be actively involved in HIV \& AIDS at the work place as leading by example will help influence the employees to take HIV \& AIDS seriously which will eventually help improve organisational culture and conduct of employees in the workplace.
\end{abstract}

Keywords: Personalisation of HIV/AIDS, Management Attitude and Behaviour, Reasonable Accommodation Principle

\section{Introduction}

HIV \& AIDS has become a global crisis and has proven to be one of the most destructive epidemics over the last 30years. UNAIDS/WHO in Huang [6] postulated that there are an estimated 33 million people living with HIV \& AIDS in the world by 2007 . Stopping and reversing the spread of HIV \& AIDS has become one of the eight Millennium Development Goals (MDGs), showing the determination by world leaders in addressing HIV/AIDS issues. (United Nations Malaysia [14]. The Government of Zimbabwe has fully endorsed this global commitment which seek to make an AIDS-free generation a reality, by coming up with a number of statutory guidelines (national HIV/AIDS policy, behavioral strategies, Statutory Instrument 202 of 1998, Labour Act, NSSA Act) to among others. HIV/AIDS can be transmitted through sexual relations with infected person, sharing of needles and other injecting equipment.

The main focus of this paper is to assess management's personal attitudes towards HIV/AIDS programmes and services offered at their work place organizations. According to Petzer [9] understanding why people behave in a certain way whilst putting themselves at risk would be helpful in identifying barriers to change and possibly identify areas that need reinforcement in HIV/AIDS intervention. While it is assumed that most people in management have sufficient knowledge of HIV/AIDS Perkel [8] argues that knowledge of HIV/AIDS and methods of protection remain inadequate as a modifier of risky behaviours. Behavioural change thus remains the only hope to reduce HIV/AIDS infection and one such behaviour that needs to be addressed in most 'employers' is the perception that HIV/AIDS programmes are meant for employees only.

\section{Background}

\subsection{Organisational Approach to HIV \& AIDS at Work Place}

Since the enactment of International Labour Organization (ILO) code of practice on HIV/AIDS, Southern African Development Countries (SADC) HIV/AIDS policy and the Zimbabwe National Policy Framework, there has been a 
growing realization that institutionalizing HIV/AIDS prevention programmes in the workplace is a necessity. Most companies in Zimbabwe have been able to come up with organizational HIV/AIDS policy framework to cater for both employers and employees. It should however be noted that both HIV/AIDS statutes, government and organizational approach to HIV/AIDS has been heavily emphasizing on protection of employee from being discriminated, victimised, unfairly treated among others by the employer. The employer in this case refers to management representatives who have been viewed as responsible enough to ensure that as they provide HIV \& AIDS programmes and services they can also access these services. Many organizations live in a state of denial when it comes to the issue of personalization of HIV/AIDS issues, hence the need of this study to encourage collective workplace responses that are relevant to both employees and employers. When we look at organizational response to the pandemic, there is need to look at all people in the organization, be it management representatives or employees. As we look at people we cannot ignore their feelings, emotions, personal experiences, beliefs and prejudices. It is therefore important to understand what shapes management's behaviour at the work place. Most research has focused on issues that affect employees - response to HIV/AIDS issues, thus more of rubberstamping the legal framework that has the employee 's protection syndrome, yet there is no research in Zimbabwe that has addressed factors that influence management 's personal behaviour and attitudes towards HIV/AIDS issues at the work place. Management teams are made up of people and they are not immune to HIV/AIDS. The main question to be answered is whether the employer considers himself/herself to be part of the focus group that is in danger from HIV/AIDS. Does the employer feel that he is part of the equation? The study feels that if the employer is encouraged to think from a personal perspective rather than brainstorming hypothetical HIV/AIDS issues and ideas this would go a long way in reducing stigma and discrimination and address the misconceptions and myths of HIV/AIDS, (Smith \& Project Empowerment [12].

The President of Zimbabwe in his opening remarks at the $2^{\text {nd }}$ National HIV Conference 2011 castigated irresponsible sexual behaviour by people in positions of authority and blamed them for fuelling HIV/AIDS transmission. Most research carried out has identified low level employees as at higher risk of contracting HIV/AIDS due to low level income, poverty, poor working conditions and low educational levels among others. However while employees may indulge for survival strategies, but some low level employees have sexual relations with people in authority in order to fulfill their poverty gap. It is argued that it is important that when organizations conduct risk assessment for their various staff categories, they consider the potential exposure of their employees to the high risk areas in account (Public Service HIV and Aids Workplace Programmes, [10], yet human feelings, emotions, beliefs and prejudices are not always influenced by the extent at which one is exposed to risk. While some employees may be highly exposed to risk for different reasons, but there is someone who may have a big heart to assist the needy while taking advantage of what is available. This brings us to the issue of personalization the impersonal. There is no research to prove that those who indulge in unsafe sex are doing it to fulfill monetary needs only hence Jackson (2002:294) [7] argues that it is in the interest of both employers and employees to mount effective HIV/IDS awareness and prevention strategies to keep healthy productive workforce. A healthy productive workforce includes both employees and 'employers' management. According to the Family Health International (2003: 109) [4] 'control of HIV epidemic differs from that of other infectious diseases, because of the complex and personal nature of the risk behaviours that drive its spread'. This sums it up that there could be other personal factors that could drive management in multiple sexual relations making them prone to HIV/AIDS.

\subsection{Management's Response to HIV \& AIDS at Work Place}

Management's response to HIV \& AIDS issues at work place have been shaped by a number of factors including the high HIV \& AIDS prevalence rate within their area of operation, the level of benefits available to the work force and the level of knowledge and awareness by business leadership of the real and potential impacts of the epidemic http://data.uniaids.org/publicatio/irc-pub05/jc44 [15] According to the Conference Board ; New York [2] the employer (management) motives for addressing HIV \& AIDS are for providing welfare of employees, safety and prevention, legal implications like discrimination, compliance, health care cost, absenteeism due to illness, public image, turnover, community problems with HIV \& AIDS and the concern that others are doing it. This clearly shows that the employer's (management)'s main motivation is to minimize the impact of HIV \& AIDS on business operations and employees. While it can be assumed that when HIV \& AIDS policies and statutory documents incorporate 'employers'(management), when they refer to employees this has not been supported on the ground as indicated by poor attendance by management to HIV \& AIDS programmes at work place. This is supported by research Conference Board ; New York [2] that one of the major challenges faced by prevention programmes is that they are poorly attended by senior management and professionals, yet no one is immune to the deadly disease. According to UNIAIDS (http://docs.google.com/viewer? $\mathrm{a}=\mathrm{v} \& \mathrm{q}=$ cache) [17] the establishment of a comprehensive and sustained HIV \& AIDS programmes with appropriate policies depends on the creation of genuine management commitment to the organization. A forceful manager who publicly endorses and collaborates on the programme will help generate enthusiasm for it across the organization. Such a forceful manager understands and appreciates that HIV \& AIDS knows no boundary and the human being is the transmitter 
of the disease. Work place HIV \& AIDS management requires both employers and employees to realize that they are all at risk of contracting HIV \& AIDS.

While many organizations have recognized the need for developing work initiatives and policies in response to HIV \& AIDS the most daunting challenge now is whether employers (management) should develop their own organizational policies and programmes in support of the Millennium Development Goal (MDG) of aids free generation. Research by UNIAIDS (http://data.uniaids.org/publicatio/irc-pub05/jc44 ) [16] however has shown that there is no need of reinventing the wheel as far as policies are concerned but what is needed is willingness by both employer and employee to personalize HIV \& AIDS and understand that everyone has a responsibility of reducing the transmission of the pandemic .

The research is guided by the Health Belief Model (HBM) which attempts to explain a variety of human behaviours by linking knowledge to attitude and behaviour. The model was put forward by Rosenstock, Strecher \& Becker [11]. It holds that health behaviour derives from an own individual's socio-demographic characteristics, knowledge and attitudes. The model shows that an individual behaviour and attitudes could be influenced by one's sex, race, religion and education. It shows that one's background has an impact on one's perceptions and attitudes which will result in one's actions. Other key variables of the HBM include the perceived threat, perceived benefits, perceived barriers, cues to action (physical symptoms of a health condition, media publicity etc) and self-efficacy. According to Denson [3], people may examine and possibly change their sexual practices as a result of external motivators such as public education and campaigns. However the model does not take into consideration other factors such as environmental or economic factors which may also influence behaviour. In addition, it does not include the influence of social norms and peer influences on people's decisions regarding health (Denson) [3].

The study also borrows from the AIDS Risk Reduction Model (ARRM) put forward by Catania, Kegeles \& Coates in [1]. The model has three stages which are recognition and labeling of one's behaviour as high risk, commitment to change and action. Stage 1 involves one being able to identify sexual activities associated with HIV/AIDS transmission, believing that one is personally susceptible to contracting HIV and believing that HIV/AIDS is undesirable. This is where an individual personalize himself/herself as playing a contributory role that contributes to HIV/AIDS. This is supported with the UNIAIDS phrases which say 'HIV/AIDS begins with you' [14].

The second stage requires the individual to be committed to change taking into cognizance the associated costs and benefits, knowledge of the health utility and joy associated with sexual practice. Management involvement as individual beings on self-directed care and self-determination can help conquer the HIV/AIDS issues hence managers behavioural commitment is of vital importance. On the other hand the third stage requires one to take action. This involves information seeking, obtaining remedies and enacting solutions. Stage three deals with self-esteem, sexual partner's beliefs and behaviours, prior experiences in one's life and seeking solutions to remedy the past.

It should however be noted that ARRM has a general limitation in that it focuses on an individual forgetting that it takes two to tangle, hence some women/men in management may feel that they are at risk simply because of their partners' unsafe sexual tendencies.

\section{Methodology}

The study used a qualitative survey to solicit data from managers from both public and private sector in Gweru urban industries, Midlands Province in Zimbabwe. Group discussions of people in positions of authority were carried out to gather information from management due to its small sample size. The survey questions were crafted basing on the objectives of the research paper.

Both secondary and primary sources of data were used in this study. The primary source was gathered from the respondents who participated in the study and those that completed the questionnaire. The secondary data sources used by the researcher included documentation and archival records for providing HIV/AIDS programmes and services offered by the organizations and records of beneficiaries. It should however be noted that due to confidentiality the researcher only managed to get summarized reports of the records from the health and safety units in the organization. Secondary data sources such as publications from government departments like National AIDS Council and Media Houses, company records and the internet also provided with much information on the literature review of the research problem.

\section{Discussion}

\subsection{Knowledge and Responsibility of an HIV \& AIDS Free Generation}

Response on the knowledge that everyone is potentially at risk in contracting HIV \& AIDS, $100 \%$ of the respondents said they were fully aware of that and of the millennium goal of an HIV \& AIDS free generation by 2020. Managers further explained that it was because of this knowledge that they were trying to comply with the international and national strategy to fight HIV \& AIDS by mainstreaming HIV \& AIDS at the work place. This is supported by UNIAIDS (4) when it postulates that management in industries embark on HIV \& AIDS programmes for compliance and with business interests at heart, eg the Anglo Coal of South Africa and the Standard Chartered Bank of the United Kingdom who established extensive peer education and preventions campaigns for work force and dependence (http://docs.google.com/viewer? $\mathrm{a}=\mathrm{v} \& \mathrm{q}=$ cache) $\quad[17] . \quad 5 \%$ of the 
respondents however were of the view that their lives were at high risk of the pandemic as they had the financial power to 'take any girl' to bed as alluded by one of the managers.

When asked on whether they knew that they were responsible for stopping the transmission of HIV \& AIDS at work place, all of them agreed that they now view management of HIV \& AIDS as an organizational issue which however was given little attention. The respondents' argument was that the fact that they were familiar with the programmes provided to low level employees, was sufficient knowledge to inform their behaviour. When the researcher insisted to find out on how many of the people in management had privilege to the content of HIV \& AIDS programmes provided at work place, only $10 \%$ of respondents who worked in the health section and human resources office had details of HIV \& AIDS programmes content. These had privy to the information because of the nature of their jobs.

\subsection{Management's Personal Attitudes and Behaviour towards HIV/AIDS Issues at the Work Place}

When asked whether they think that they should be actively involved in HIV \& AIDS programmes at work place $70 \%$ of the respondents highlighted that they did not have time to participate in the programmes. These managers however argued that they were in full support of the programme and had set aside resources towards its implementation. $20 \%$ of respondents indicated that they were willing to participate but were afraid that they could be stigmatised for such a move. This clearly shows that even low level employees have been cultured by the way these programmes are run at work place to believe that they are meant for low level employees only, hence HIV \& AIDS work place management requires forceful managers that lead by example to change the perception that' the disease is out there'. It is also interesting that while management fund and support HIV \& AIDS programmes that preach that employees should not discriminate each other, they themselves are also afraid of being discriminated by subordinates and peers. This strongly supports the notion that there is need for personalisation of HIV \& AIDS programmes by both employers and employees.

$30 \%$ of management were of the view that if ever they were to participate in HIV \& AIDS programmes, the co-ordinators of these programmes were to craft programmes for their level of operation as they could not be seen mingling with low level employees. Some managers suggested that possibly management should be given some incentive to attend conferences / workshops outside work place that addresses HIV/AIDS at least once a year as a way of motivating them to grapple with the deadly disease. This is supported by the Conference Board ; New York [2] which concluded that management themselves view the matter as sensitive and hence leave it to individuals to deal with it.

$75 \%$ of non-managerial respondents were of the view that management were the key drivers of HIV/AIDS policies and programs at work places hence their attitudes and behaviours had a huge impact on subordinates and peers. This was strongly supported by $10 \%$ of respondents who viewed lack of personalisation of HIV/AIDS at work place to include lack of financial support towards running these programs and lack of commitment to see the HIV/AIDS policies implemented. All managers who responded agreed that they do not view HIV/AIDS issues as belonging to the strategic table hence little priority was given to address the pandemic at work. $15 \%$ of respondents believed that HIV/AIDS issues were a mandate of non-governmental organisations, thus reflecting ignorance on the part of some managers and justifying further the issue of lack of personalisation. If management is not committed very few HIV/AIDS programs can be successfully implemented at the workplace.

\subsection{Impact of Lack of Personalization HIV/AIDS by Management}

The findings revealed that $80 \%$ of managerial respondents believed that if there could be any reparations these were more of personal issues which they believed they could deal with individually. This is supported by the UNIAIDS research [16] which explains that leaders believe that they have enough resources to suppress the pandemic, yet in reality HIV/AIDS continue to claim lives regardless of one' s political power, position at work, race, economic power and gender differences. Without strong, confident leadership, workplace programs can-not take the bold steps required to challenge the existing conditions. Personalisation of HIV/AIDS helps managers to come up with the best solutions (reasonable accommodation) as if he/she is infected. Lack of personalisation by management also leads to a vacuum in operation of the policies at the workplace as there is no management commitment to facilitate proper implementation of the planned workplace interventions.

The other impact is that the overall productivity of workforce declines. Also overall labour costs were said to increase in all these organisations as those infected and affected increased their uptake of medical benefits, payment of overtime and the application of reasonable accommodation principle.

The other impact of lack of personalisation of HIV/AIDS by management was that the morale for subordinates was low and discipline and concentration of other employees was disrupted. It was also established that managers who were infected were psychological unstable sometimes also culminated with health problems thus affecting their performance in delivering organisational goals. This was supported by sick leave forms for senior managers that were produced by one of the organisation.

Hersey \& Blanchard quoted in Perkel [8] argues that lack of encouragement from management also causes employees to end up in indulging in risk behaviours which as a result cause the spread of HIV/AIDS at a workplace. 


\section{Conclusion}

It was concluded that management supported HIV/AIDS at workplace and they personally believed that they could address their own HIV/AIDS issues on their own without involving the employer. Managers had knowledge of HIV/AIDS but were reluctant to act on this knowledge when it comes to addressing their own HIV/AIDS status.

\section{Recommendations}

- $\quad$ Managers to participate in HIV/AIDS programmes at workplace.

- Managers should volunteer to disclose their status and act as role models in this quest as this help eliminate stigma.

- Managers to employ councilors or psychologists who will provide counseling services to all employees at workplace.

- Managers to desist from crafting policies they do not implement.

\section{References}

[1] Catania J. A., Kegeles S. M. \& Coates T. J. (1990), Towards understanding of risk behaviour. An Aids risk reduction model, (ARRM), Health Education Quarterly vol 17 (1), pg 53-72.

[2] Conference Board New York (1997): The business response to HIV/AIDS. Impact and lessons learned, New York.

[3] Denson J. (1996) Behaviour change, a summary of four major theories. Behavioral Research Unit, Family Health International/AIDSCAP.

[4] Family Health International (2003). Evaluating programmes for HIVAIDS prevention and care in developing countries: A handbook for managers and decision makers, Family International Implementing AIDS Prevention and Care (IMPACT)
[5] Government of Zimbabwe, Statutory Instrument 202 of 1998 ( Harmonized Labour Relations Amendment Act of 2003), Printflow, Harare.

[6] Huang L. \& Crothers K. (2009), HIV associated opportunistic pneumoconiosis. National Center for Biotechnology Information, USA.

[7] Jackson H, (2002) AIDS AFRICA, Continent in Crisis, SAfAIDS, Harare

[8] Perkel A. K. (1991) Psychosocial variables in the transmission of AIDS, Master's Thesis, Cape Town, University of Western Cape.

[9] Petzer K. (2003), HIV/AIDS/STD Knowledge, attitudes \& beliefs \& behaviours in rural South African Adults Population, South African Journal of Psychology 33(40) 250-260..

[10] Public Service HIV/AIDS workplace programs (2007): Public Health Service Outstanding Unit: for extraordinary vision, professional leadership, teamwork \& dedication in responding to the President's Emergency Plan for Aids.https:docs.google.com/viewer? $\mathrm{a}=\mathrm{v} \& \mathrm{q}=$ cache.

[11] Rosenstock I., Strecher V. \& Becker M. (1994), The Health Belief Model \& HIV risk behaviour change. Methods of behavioural interventions pg 5-24. Plenum Press.

[12] Smith R. \& Project Empower (2010) The means is the end. Reflections on the process of developing HIV/AIDS workplace policies. International Training \& Research Centre.

[13] The World Bank 1998, World Development Report, World Bank, Washington DC.

[14] United Nations (2005): UN special session on HIV/AIDS seeks to spur massive global response to crisis. Malaysia.

[15] http://docs.google.com/viewer?a=v\&q=cache (June 2012), HIV/AIDS \& the work place. Forging innovative business responses.

[16] http://data.uniaids.org/publicatio/irc-pub05/jc44-( June 2012)The business response to HIV/AIDS. Impact and lessons learned.

[17] http://docs.google.com/viewer?a=q=cache ( July 2012) Elements of a comprehensive response to HIV/AIDS in the work place. 